\title{
Indian Coal Industry: Trends and Challenges
}

\author{
M.V.Raghavalu*
}

\begin{abstract}
Coal is an most important fuel resource for generating energy across the world. An estimation of world coal resources reveals that India has $10 \%$ of the total resource and more than 55\% of the current total commercial energy needs are met by coal. In view of the importance of coal as an important fuel, this study attempts to study the trends on actual coal resources, production, demand, and supply, and challenges faced by the coal industry in the Indian economy. It also suggests ways that would help in the efficient use of coal resources so that it can be preserved for future generations. The Central and the concerned State governments have to take bold steps to safeguard the existing coal reserves through suitable policies and serious steps not only for the future generations but also for present generations and maintenance good environmental conditions.
\end{abstract}

Keywords: Coal industry, Coal reserves, Environment, Energy.

\subsection{Introduction}

Coal is named as black gold and it one of the most important fuel resources for generating energy across the world. An estimation of world coal resources reveals that USA had $22.6 \%$ of the total coal reserves followed by Russia (14.4\%), China (12.6\%), Australia (8.9\%), and India (7\%) [Energy Information Administration]. India is also a major coal producer as well as coal consumer in the world. In India, more than 55\% of the current total commercial energy needs are met by coal. Interestingly, fuel wise electricity generation reveals that the highest source is accounted for by coal at $59 \%$ followed by hydro sources $(25 \%)$, gas (11\%), nuclear and wind sources $(2 \%)$ and diesel only at $1 \%$. Further, $76 \%$ of coal consumed in the country is used by the power sector and that $67 \%$ of the electricity generated comes from coal. Owing to heavy usage of coal, the share of coal is expected to come down marginally to about 50 per cent of energy needs by the end of 2024-25 and 47 per cent in 2031-32.

*Associate Professor, Department of PG Studies in Economics, Government First Grade College, Karnataka. 
In view of the given situation in coal industry, an attempt is made to analyse the trends on actual coal resources, production, demand, and supply and challenges faced by the coal industry in the Indian economy. The study also provides suggestions that would help in the efficient use of coal resources so that it can be preserved for times to come.

\subsection{Trends in Coal Industry in India}

\subsection{Coal Reserves}

Coal is an important energy source, which plays a crucial role in the economic development of our country. Indian coal is characterised by the following quality aspects: a) Lower to medium grade coal; b) high ash content; c) low moisture content; and d) low sculpture content. The government has recognised the need for scientific development in coal industry from the early years of planning. Over the past three decades, intensive exploratory efforts have increased our knowledge of coal reserves. Various measures were introduced to improve mining technique, optimize utilization and stimulate resources and development of this industry under the Five Year Plans. The establishment of the National Coal Development Corporation in 1956 did not improve the matters and therefore, coal mines were nationalised in the early 1970s. This led to the introduction of new technology, standardisation of technology, and creation of infrastructural facilities. As a result of these efforts, India is currently the third largest producer of coal, and contributes 8 percent of the total coal production in the world (IBM, 2012). Coal mining in India constitutes a share of $80 \%$ in the total mining; with the rest $20 \%$ distributed among various raw materials such as gold, copper, iron, lead, bauxite, zinc etc.

According to the Geological Survey of India, the coal reserves of India up to the depth of 1200 meters have been estimated by at 301.56 billion tones as on $1^{\text {st }}$ April 2014 . However, the major coal deposit places are in Jharkhand, Odisha, Chhattisgarh, West Bengal, Madhya Pradesh, Andhra Pradesh and Maharashtra (Table 1 and Figure1).

\subsection{Coal Production}

Coal production increased from over 30 million tonnes in 1947 to around 60 million tonnes in late 1960s, by the implementation of several legal and institutional changes in the sector. However, in the late 1960s, coal industry faced a demand shortfall due to low prices of petroleum products. With a view to analyze the causes and to suggest a comprehensive energy policy, Fuel Policy Committee (FPC) was set up in 1970. FPC made a comprehensive analysis of energy sector and concluded that coal 
should be considered as primary source of energy in the country.

Table 1: State-wise Coal reserves in India (as on 1-4- 2014)

\begin{tabular}{|l|l|l|l|l|}
\hline State & Proved & Indicated & Inferred & Total \\
\hline West Bengal & 13403 & 13022 & 4893 & 31318 \\
\hline Jharkhand & 41377 & 32780 & 6559 & 80716 \\
\hline Bihar & 0 & 0 & 160 & 160 \\
\hline Madhya Pradesh & 10411 & 12382 & 2879 & 25673 \\
\hline Chhattisgarh & 16052 & 33253 & 3228 & 52533 \\
\hline Uttar Pradesh & 884 & 178 & 0 & 1062 \\
\hline Maharashtra & 5667 & 3186 & 2110 & 10964 \\
\hline Odessa & 27791 & 37873 & 9408 & 75073 \\
\hline Andhra Pradesh & 9729 & 9670 & 3068 & 22468 \\
\hline Assam & 465 & 47 & 3 & 515 \\
\hline Sikkim & 0 & 58 & 43 & 101 \\
\hline Arunachal Pradesh & 31 & 40 & 19 & 90 \\
\hline Meghalaya & 89 & 17 & 471 & 576 \\
\hline Nagaland & 9 & 0 & 307 & 315 \\
\hline Total & $\mathbf{1 2 5 9 0 9}$ & $\mathbf{1 4 2 5 0 6}$ & $\mathbf{3 3 1 4 9}$ & $\mathbf{3 0 1 5 6 4}$ \\
\hline
\end{tabular}

Source: Coal Exploration and Resources, Govt. of India.

Figure 1: State-wise Coal reserves in India (as on 1-4- 2014)

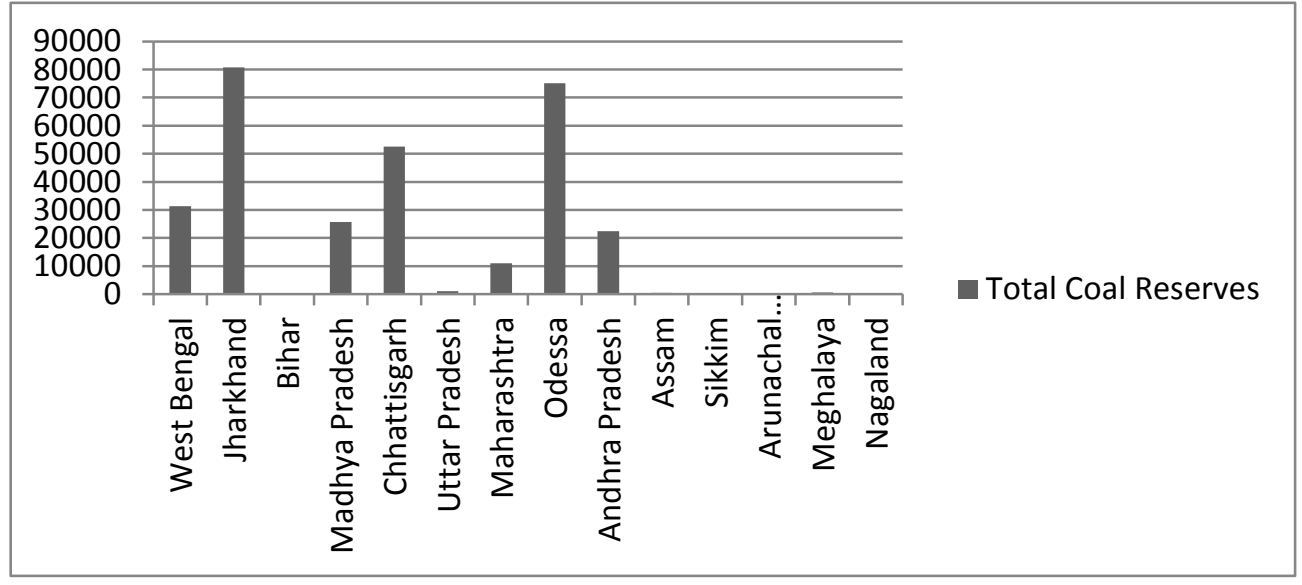

Source: Coal Exploration and Resources, Government of India 
The coal industry in India has dominating, more than 90 per cent of India's production concentrated in the public sector. Amongst the public sector companies, CIL accounts for the largest proportion. Its share in total coal production is more than 80 per cent. The private sector share in total coal production is only 9 per cent in 2011-12 and has increased by only 3 per cent from 2005. Table 2 shows the category-wise coal resources of India as on $1^{\text {st }}$ April 2014. As per the table, the major resource of coal $(88 \%)$ is accounted for by the non-cooking sector.

Table 2: Type and Category-wise Coal Resources of India (as on 1-4-2014)

\begin{tabular}{|l|l|l|l|l|}
\hline Type of Coal & Proved & Indicated & Inferred & Total \\
\hline A) Cooking & & & & \\
\hline Prime coking & 4614 & 699 & 0 & 5313 \\
\hline Medium coking & 13303 & 11867 & 1879 & 27049 \\
\hline Semi coking & 482 & 1004 & 222 & 1708 \\
\hline Sub-total Coking & 18400 & 13569 & 2101 & 34070 \\
\hline B) Non- coking & 106916 & 128838 & 30249 & 266002 \\
\hline C) Tertiary coal & 594 & 99 & 799 & 1493 \\
\hline Grand Total & $\mathbf{1 2 5 9 0 9}$ & $\mathbf{1 4 2 5 0 6}$ & $\mathbf{3 3 1 4 9}$ & $\mathbf{3 0 1 5 6 4}$ \\
\hline
\end{tabular}

Source: Annual Plan, Ministry of Coal, 2013-14, Coal Controller Organization and Planning commission.

\subsection{Coal supply and Demand}

India is a major player in the mining of coal. By the end of 2011, the production of coal was 431.32 MT as against targeted 452 MT of at 2012 financial year ending. The total number of coal/lignite based thermal power plants are 88 , with installed capacity of $80458 \mathrm{MW}$, which consume 407.61 MT of coal. Further, coal/lignite based thermal power plants increased to 90 with installed capacity of $8379 \mathrm{MW}$ production during 2012. The annualised production and its growth rates are shown in Table 3. As seen in the Table, the annual growth rate of coal production in India is the highest at 7.73 per cent in Second Five Year Plan followed by 7.24 per cent in Sixth Five Year Plan and the lowest at 1.24 per cent in Fourth Five Year Plan.

Table 4 shows that the percentage of achievements over targets is 90 under the reference period. It is observed from Table 4 that the performance of the industry in terms of targets and achievements is quite impressive, especially, during 2013-14. Since inception of the Five Year Plans, the demand for coal is increasing. For example, the demand has increased significantly from 549.02 MT in 2008-09 to 713.39 MT (Pro) in 
2012-13. It was estimated to be 769.69 MT for the year 2013-14(BE) and 787.03 in 2014-15(BE). The sector wise total coal demand and actual supply during 2012-13, 2013-14(BE \& AE) and 2014-15(BE) are shown in Table 5 and Figure 2.

Table 3: Plan-wise Coal Production Trends and Annualized Growth Rate (CAGR)

\begin{tabular}{|l|l|l|l|}
\hline Plan & Terminal Year & Production (Mt) & CAGR (\%) \\
\hline First Five Year Plan & $1955-56$ & 38.40 & -- \\
\hline Second Five Year Plan & $1960-61$ & 55.72 & 7.73 \\
\hline Third Five Year Plan & $1965-66$ & 70.30 & 4.76 \\
\hline Fourth Five Year Plan & $1973-74$ & 78.18 & 1.24 \\
\hline Fifth Five Year Plan & $1978-79$ & 102.02 & 5.47 \\
\hline Sixth Five Year Plan & $1984-85$ & 147.44 & 7.24 \\
\hline Seventh Five Year Plan & $1989-90$ & 203.36 & 6.64 \\
\hline Eight Five Year Plan & $1996-97$ & 289.32 & 4.76 \\
\hline Ninth Five Year Plan & $2001-02$ & 327.79 & 2.53 \\
\hline Tenth Five Year Plan & $2006-07$ & 430.83 & 5.62 \\
\hline Eleventh Five Year Plan & $2011-12$ & 554.00 & 5.16 \\
\hline
\end{tabular}

Source: Five year Plan Documents, Government of India.

Table 4: Targets and Achievements of Production of Coal in India

\begin{tabular}{|l|l|l|l|}
\hline Year & Target & Actual production & \% Achievement \\
\hline $2009-10$ & 435 & 431 & 99 \\
\hline $2010-11$ & $460($ Revised 440) & 431 & 94 \\
\hline $2011-12$ & $486($ Revised 440) & 435 & 90 \\
\hline $2012-13$ & $470($ Revised 464) & 452 & 96 \\
\hline $2013-14$ & 482 & 482 & 100 \\
\hline
\end{tabular}

Table 5: Coal Supply and Demand in India

\begin{tabular}{|l|l|l|l|l|l|l|}
\hline Source & $\begin{array}{l}\mathbf{2 0 1 2 - 1 3} \\
\text { BE }\end{array}$ & $\begin{array}{l}\mathbf{2 0 1 2 - 1 3} \\
\text { Actual }\end{array}$ & $\begin{array}{l}\mathbf{2 0 1 3 - 1 4} \\
\text { BE }\end{array}$ & $\begin{array}{l}\mathbf{2 0 1 3 - 1 4} \\
\text { Actual }\end{array}$ & $\begin{array}{l}\mathbf{2 0 1 4 - 1 5} \\
\text { BE }\end{array}$ & $\begin{array}{l}\text { XII Plan } \\
\text { Proj 2016-17 }\end{array}$ \\
\hline CIL & 470 & 464.95 & 492.00 & 471.09 & 520.00 & 615.00 \\
\hline SCCL & 53.1 & 52.08 & 56.00 & 47.89 & 55.50 & 57.00 \\
\hline Others & 57.2 & 50.58 & 66.55 & 52.03 & 68.25 & 123.00 \\
\hline Indigenous Supply & 580.3 & 567.60 & 614.55 & 571.00 & 643.75 & 795.00 \\
\hline Actual Imports & & 145.79 & & $168.50 *$ & & \\
\hline Demand Projected & 772.84 & & 769.69 & & 787.03 & 980.5 \\
\hline $\begin{array}{l}\text { Gap Projected to } \\
\text { be met by Import }\end{array}$ & 192.54 & & 155.14 & & 143.28 & 185.50 \\
\hline
\end{tabular}

Note: Demand is assessed by the Planning Commission at the beginning of each Annual Plan. *provisional figures up to Jan.2014. 
Owing to increase of developmental activities and insufficient production, there is a gap between demand and supply of coal, especially, in the recent years. Table 5 and Figure 2 reveal that the demand for coal during 2013-14, was estimated to be 769.69 MT, whereas the indigenous availability was estimated at 614.55 MT. The gap of 155.14 MT was projected to be met through imports. The actual indigenous supply of coal has been of the order of 571.00 MT during 2003-04. About 168.5 MT of coal was imported during 2013-14 to meet the requirement of the different sectors.

Figure 2: Demand and Supply of Coal in India

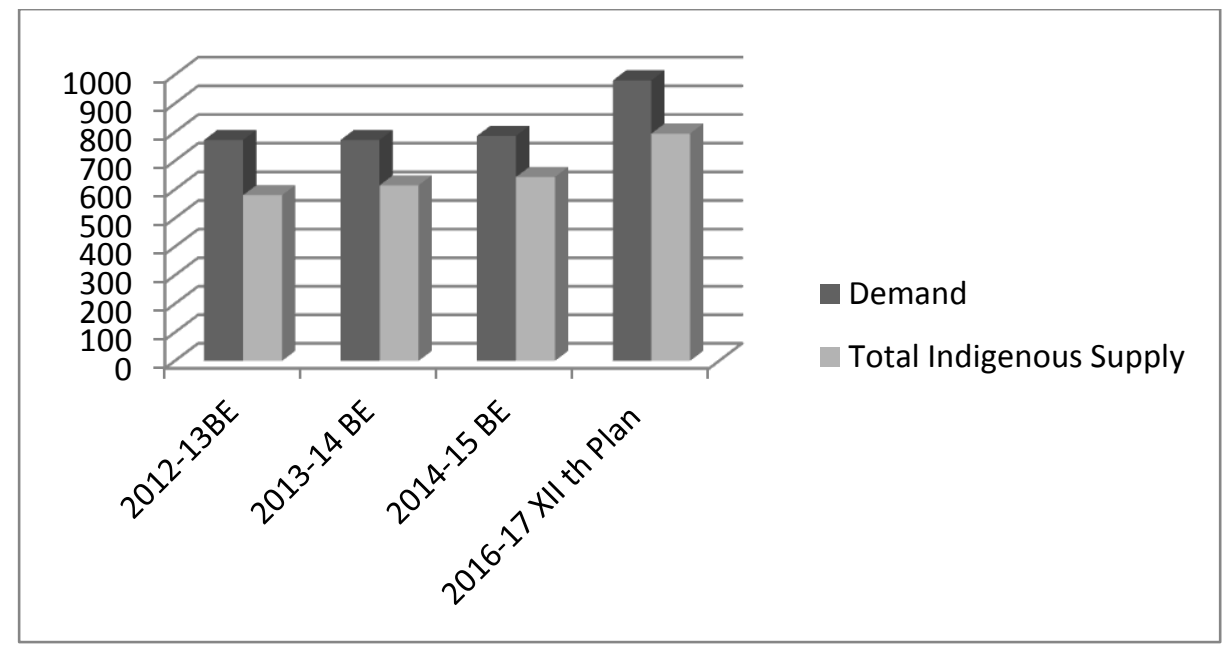

Source: Planning Commission

\subsection{Challenges for Coal Industry in India}

Even though India has good quantum of natural resources, like iron ore, manganese, lignite and coal, its usage and maintenance is insignificant. Consequently, the sector faces an increasing number of challenges. This leads to not only revenue loss to the government, but also, causes depletion of valuable reserves. In addition, it is evident from various studies that the management of the coal industry in India is not favourable, due to inefficient administration and high involvement of political leaders and officials in the administrative matters. We mention below some of the challenges faced by the coal industry in India and suggestions for the development of this industry and the Indian economy. 


\subsection{Extractable coal}

The average production target of CIL has been high from 2012 onwards. If this rate were to be applied to CIL's current reserves, the company would exhaust extractable coal supplies by 2030 . The recent studies reveal that during the period 2011 the demand for India's coal was $640 \mathrm{MT}$ and coal demand in 2030 is estimated to be at 1.5 billion tones for electricity and 2 billion tones in total. If CIL, hypothetically, were able to meet all of India's coal demand (assuming a government aspiration to meet all demand through domestic production and discounting imports), its extractable reserves would be exhausted by 2026-27. The coal industry will not be able to provide fuel to new power plants, since new coal plants would be necessary for future generations. Hence, suitable steps are necessary by concerned governments in this regard.

\subsection{Administrative challenges}

One of the important challenges in this industry is getting all the licenses due to heavy formalities. These include approvals with the environment ministry which can take around 1 to 4 years; getting the permission from the state government; and land acquisition. However, Mines and Minerals (Development and regulation) Bill, 2011 can help in solving this issue. Hence, the formalities regarding license should be simplified for the convenience of the companies concerned.

\subsection{Transparency}

Transparency is one of the important challenges in this sector. The accounts relating to production and supply transportation of the raw goods and final products from the fields to market place are important stages and in many of the cases it is misleading, resulting in heavy loss to the governments. This problem may be reduced by implementing the network based observation and proper management.

\subsection{Pricing}

As per demand and supply, fixation of price is important to any company to get more income. However, the central government fixed the prices until its delegation in 2000. The right to fix the price was given to Coal India and Singareni Collieries Company. However, the Ministry of Coal interfered with the pricing on political grounds, As a result, a D- grade variety of coal is sold at a discount of nearly $\$ 60$ per tonne, and those importing coal are doing so at this higher price, while Coal India is made to sell at lower prices to the coal companies. Sincere steps are needed in this regard. 


\subsection{Power sector reforms}

Power tariffs have been kept low due to political reasons and quality and uninterrupted power is denied to the consumers under the garb that they cannot afford it. Power reforms are a must for proper generation and distribution of power..

\subsection{Transportation and infrastructure}

Lack of transportation and lack of proper infrastructural facilities are other problems faced by this industry. The railways are established by the government, but they are insufficient and often not available timely as per the requirements of the units concerned. Transport and infrastructure facilities should be provided by the both Central and State governments with suitable policies.

\subsection{Environmental problems}

Coal mining impacts the environment and ecology to an unacceptable degree, unless carefully planned and controlled. The major environmental problems at the mining stage are destruction of forest and biodiversity, air pollution and sound pollution. Even though policies and controls are organised by the governments, its implementation is insignificant.

\subsection{Recommendations}

In view of the above challenges faced by the coal industry, the following suggestions may be useful.

1. Railway transportation needs to be improved in the coal mining areas, by the establishment of doubling of railway routes.

2. Better connectivity of railway networks to improve the transportation in the coal mining areas.

3. Enhancing the port capacities as well as evacuation efficiency and augmenting the existing capacities from existing posts.

4. High production depends on skilled human resources; hence, various facilities like hike of wages, training facilities and workshops should be started by the concerned companies.

5. Online web portals through filing of returns should be considered by State or Central governments. All transactions should follow for betterment of this sector.

6. Area-wise pollution controls should be arranged separately for this industry and strict implementation is essential. 


\subsection{The Road Ahead}

According to an expert group, the coal demand is likely to touch 1000 MT by 2016-17, much higher than estimated supply of 750 MT. The estimated power generation from the coal is likely to 161 giga-watts, with associated projected increase in post coal production. Hence, the Central and the concerned State governments have to take strong steps to safeguard the existing coal reserves through suitable policies. These policies should not only aim at maintaining good environmental conditions for the present generation but also aim at preserving coal for the future generations.

\section{References}

Aggarwal, Sanjeev. (2009). Captive Coal Mining: Issues and Challenges, available at: http://www.observerindia.com/cms/export/orfonline/documents/coal/coal/AES-ppt.pdf

BP (2005), Statistical Review of World Energy.

Fernandes, Ashis. (2013). Coal India: Running on Empty? IEEFA, Greenpeace India: GreenPeace.

Government of India (2012). Annual Report, Ministry of Coal.

Haque, Md. Emamul. (2013). Indian Coal: Production and ways to increase coal supplies. International Journal of Scientific and Research Publications, 3(2).

India Energy Book (2012). World Energy Council, Indian Chamber Committee.

Indian Chamber of Commerce. (2012). The Indian Coal Sector: Challenges and Future Outlook. 